\title{
MEASUREMENTS OF PULMONARY CAPILLARY BLOOD FLOW AND GAS EXCHANGE THROUGHOUT THE RESPIRATORY CYCLE IN MAN'1
}

\author{
BY ARTHUR B, DUUBOIS 2 AND ROBERT MARSHALL 8 \\ (From the Department of Physiblogy dind Pharinacology, Graduate Sithool of Medicine,

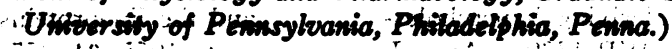

(Subinitted for publication May 13, 1957; accepted July 11, 1957)

Judging from the hemodyhanic meastrements in the heart and pulmonary circulation as jeviewed by Wiggers in 1921 (1) and studied in man by Lauson, Bloomfield, and Courriand in 1946 :(2), it seemed entirely possible that the pulmonary capillary blood flow might vary appreciably during the respiratory cycle.

Brecher and Hubay (3) reported respiratory fluctuations of pulmonary artery flow in dogs determined by implanting a bristle flow meter in the pulmonary artery. But if these respiratory variations of blood flow persisted in the pulmonary capillaries in intact man, they could conceivably create a moment-to-moment "unsteady state" which would cause errors in calculation of the respiratory gas exchange and cardiac output.

It has recently been shown that the pulmonary capillary blood flow, as measured by a new and instantaneous method, is pulsatile in time with the heart beat (4). It is the object of this study to measure pulmonary capillary blood flow by the instantaneous method throughout the entire respiratory cycle in the normal intact man.

Previous attempts to measure alveolar capillary gas exchange during the respiratory cycle have been limited to the expiratory phase alone, because expired alveolar gas can be sampled only during expiration. The present method permits measurements to be made of the exchange of gases between alveoli and capillaries during both expiration and inspiration.

\section{METHOD}

The rate of absorption of $\mathrm{N}_{2} \mathrm{O}$, a gas which is highly soluble in the bloodstream, was measured by a "mano-

1 These studies were aided, in part, by a contract between the Office of Naval Research, Department of the Navy, and the University of Pennsylvania, NR 112-323.

2 This work was done during the tenure of an Established Investigatorship of the American Heart Association.

8 Present address: The Dunn Laboratories, St. Bartholomew's Hospital, London, England. metric resplotneter technique as described previously (4): Figure 1 illustrates the principle of the method. The subject sits entirely inside $t$ body plethysmograph (a) lirge box) which has a sensitive pressure gauge. If nitrous dxide is breithed into the lungs, it is taken up by the bloot flowing through the pulmonary capillaries. As $\mathrm{N}_{2} \mathrm{O}$ leaves the gas phase, the total gas volume and pressure decrease in the closed box. The blood flow can be calculated by an equation which applies before recirculation, provided the alveolar gas tension and the solubility of the gas in whole blood are known.

In the technique previously described, the measurements of $\mathrm{N}_{2} \mathrm{O}$ uptake were made when the breath was held with the glottis open and changes in pressure in the box were due almost entirely to the uptake of $\mathrm{N}_{2} \mathrm{O}$.

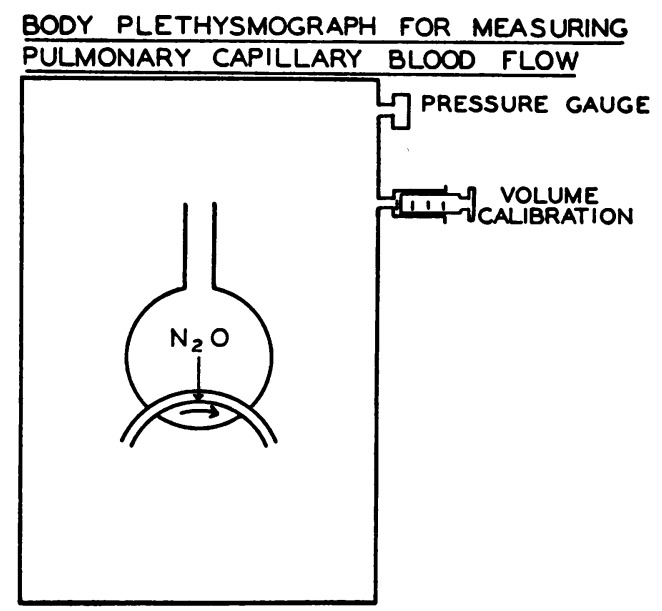

Fig. 1. Diagram Illustrating the Princtple of Measurement of Pulmonary Capillary Blood Flow

During normal respiration the pressure in the box is affected by other factors. First, changes in temperature and saturation of the respired gas cause fluctuations in plethysmographic pressure. These changes were eliminated by rebreathing from bags at body temperature saturated with water vapor. Secondly, changes in alveolar pressure during airflow also produce changes in box pressure (5) but if the airflow is recorded a correction can be applied for the pressure changes due to this cause.

Apparatus. The body plethysmograph used in these investigations has been described previously $(4,5)$. A double chamber was used; one half was occupied by the 


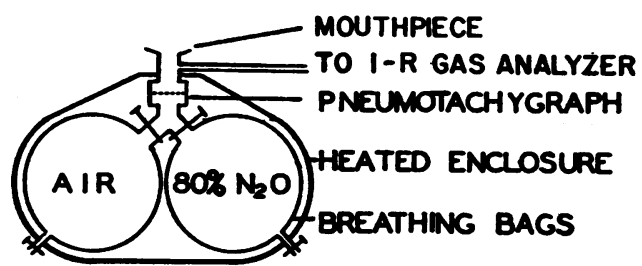

Fig. 2. Apparatus Used for Rebreathing AIr or 80 Per Cent $\mathrm{N}_{2} \mathrm{O}$ Saturated with Watzr Vapor at $37^{\circ} \mathrm{C}$.

subject while the other half at atmospheric pressure merely served to damp sound waves on the reverse side of the manometer. A Lilly capacitance manometer measured the differential pressure between the two chambers and responded with a sensitivity of $0.4 \mathrm{~mm}$. deflection per $\mathrm{ml}$. change of gas volume in the subject's chamber. The natural frequency of this manometer was approximately 200 cps.

Suspended from the roof of the chamber was the heated enclosure containing the gases to be rebreathed (Figure 2).* The enclosure consisted of a wire mesh cage encircled by a heating coil. The enclosure was covered by cloth for thermal insulation and by a polyethylene bag to prevent passage of warm air to the outside of the bag as the subject rebreathed. Inside the enclosure were two 4-liter anesthesia bags, one containing air and the other a mixture of 80 per cent $\mathrm{N}_{2} \mathrm{O}$ and 20 per cent $\mathrm{O}_{2}$. The necks of the bags were occluded by clamps and were connected via a 1 -inch bore $T$ piece to a small heated flow meter and mouthpiece. The gases put into the bags had been saturated with water vapor by passing them through DeVilbiss nebulizers. The temperature of the heating coil surrounding the enclosure was controlled by means of a variable transformer to maintain the air temperature at $37^{\circ} \mathrm{C}$. A $1-\mathrm{mm}$. bore polyethylene tube led from the mouthpiece of the breathing apparatus to a rapid infrared gas analyzer. ${ }^{5}$ This analyzer had a range of zero to 100 per cent $\mathrm{N}_{2} \mathrm{O}$ and was located outside the respiratory chamber.

After passing through the analyzer, the gas sample was returned to the chamber by a continuously pumping system through a polyethylene tube. Electrocardiograph leads and an esophageal pressure tubing passed to the outside of the chamber for amplification and continuous recording, by Hathaway oscillograph galvanometers of suitable sensitivity and frequency response, on 6-inch wide photosensitive paper moving at a speed of 1 inch per second. The subject's chamber was vented to the atmosphere at will by a solenoid operated valve. The plethysmograph was calibrated by a small pump which had

4 Previous attempts to heat and saturate the entire air inside of the plethysmograph had resulted in discomfort of the subject. However, in the present arrangement the air surrounding the body of the subject was not heated.

- Liston-Becker model 16. Case flushed with 100 per cent $\mathrm{CO}_{2}$ to discriminate against the latter. Lag (Figure 3) was about 0.2 second. a to and fro stroke of $30 \mathrm{ml}$. at a rate of 2 cycles per second.

Procedure. After the subject entered the chamber, it was closed and intermittently vented during a 2-minute warm-up period necessary for the thermal pressure drift to become negligible. Wearing a nose clip, he then breathed approximately half-way out, placed his mouth on the rubber mouthpiece," unclamped the 4-liter bag of air, took a full inspiration from the bag, and then rebreathed at normal rate and depth for a period of $20 \mathrm{sec}-$ onds. The clamp was replaced on the neck of the air bag. After 2 minutes of recovery, he again breathed half-way out, put his mouth on the mouthpiece, unclamped the other gas bag which contained 4 liters of a mixture of 80 per cent $\mathrm{N}_{2} \mathrm{O}$ and 20 per cent $\mathrm{O}_{2}$, took a deep breath of the mixture and then rebreathed at a normal rate and depth for a 20 -second period. At the end of that time, he removed his mouth from the mouthpiece. Continuous recordings were made during the control period on air and during the experimental period on nitrous oxide. The pressure gauges and nitrous oxide meter were calibrated. This procedure was carried out during normal quiet breathing and repeated with the subject breathing through added resistance.

A breathing resistance consisting of glass wool packed into a 1-inch breathing tube was interposed between the mouth of the subject and the rebreathing apparatus. The value of this resistance, measured by pressure-flow tracings at $0.5 \mathrm{~L}$. per second, was $10 \mathrm{~cm} . \mathrm{H}_{2} \mathrm{O}$ per $\mathrm{L}$. per second, which is in the range of moderate to marked obstruction to breathing. The usual procedures rebreathing air and $\mathrm{N}_{2} \mathrm{O}$ were carried out, but in addition esophageal pressure fluctuations were recorded from an air-filled balloon $10 \mathrm{~cm}$. long placed in the lower third of the esophagus, to show that fluctuations of pleural pressure were taking place, as seen in Figure 3, and to rule out changes of resistance which might otherwise affect the correction for gas compression during breathing.

The usual respiratory cycle included approximately three heart beats during inspiration and three beats during expiration. Additional experiments were performed to determine the effect upon blood flow of slow breathing, at the rate of approximately five heart beats during inspiration and five during expiration, i.e., about seven respirations per minute.

During ordinary breathing, there was but little variation of heart rate throughout the respiratory cycle. However, during slow breathing there was considerable sinus arrhythmia. Atropine, $1.2 \mathrm{mg}$., was administered subcutaneously to two subjects to diminish the sinus arrhythmia, in an attempt to separate the mechanical factors from the vagal factors which might affect the pulmonary capillary blood flow.

Calculation. The first respiratory cycle rebreathing $\mathrm{N}_{2} \mathrm{O}$ was neglected, but the next few cycles (Figure 3 ) were measured provided they were "on scale" and prior to recirculation. As many as five consecutive cycles were sometimes measured.

The type of record obtained is shown in Figure 3. 

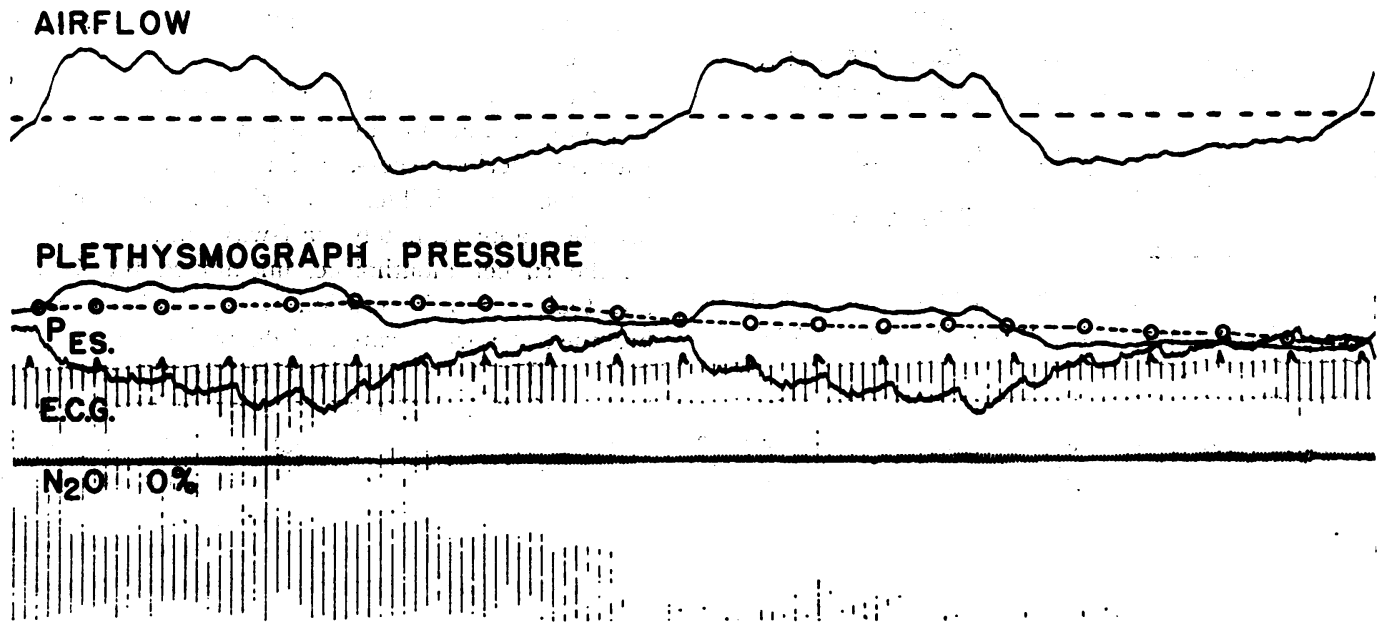

Fig. 3A. Stmultaneous Recordings of Pneumotachygram, Plethysmographic Pressure, Esophageal Pressure and Electrocardiogram, with 0 Per Cent $\mathrm{N}_{2} \mathrm{O}$ in the Mouthpiece White the Subject Was Breathing Atr During the Control Period, Prior to Breathing Nitrous Oxme (FigURE 3B)

Calibration factors and paper speed are same as for Figure 3B. The purpose of the record is to show the magnitude of the correction factors discussed in the section on calculations, particularly the relationship between plethysmographic pressure and the rate of airflow at the mouth.

During the control period on air there were respiratory fluctuations of the plethysmographic pressure proportional to the rate of airflow at the mouth of the subject. With the low rates of airflow obtained during normal breathing (usually less than $0.5 \mathrm{~L}$. per second) this relationship between recorded airflow and plethysmographic pressure was linear and could be measured either from the tracing obtained during normal breathing or during panting at the end of the record. The relationship between deflection recorded by the flow meter and plethysmographic pressure was approximately the same whether breathing

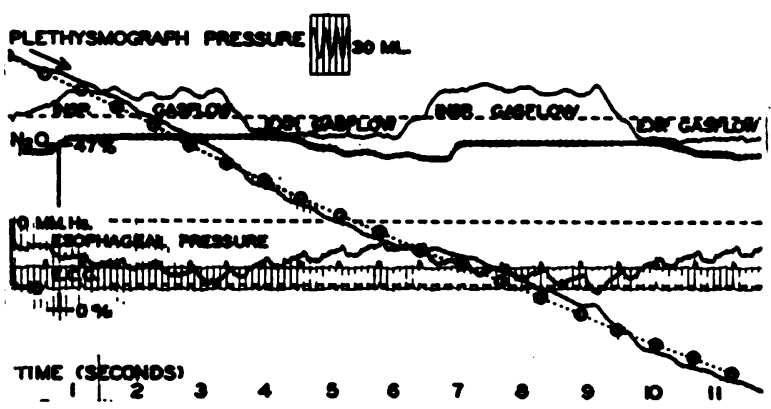

Fig. 3B. Sncultaneous Recordings of Pleteysmographic Pressure, Pneumotachygram, $\mathrm{N}_{2} \mathrm{O}$ Per Cent in Expired Air, Esophageal Pressure and ElectroCARDTOGRAM

The record reads from left to right. The $R$ waves of the ECG have been touched up. Inset is calibration of plethysmographic pressure. This subject had atropine. Dotted line through circles represents plethysmographic pressure change attributable to gas absorption, a correction having been made for resistance to airflow. air or the foreign gas mixture (approximately 50 per cent $\mathrm{N}_{2} \mathrm{O}$ ).

The plethysmographic pressure during the rebreathing of $\mathrm{N}_{2} \mathrm{O}$ was read and the correction subtracted proportional to the rate of airflow. A second correction was applied for the trend of the respiratory exchange difference for $\mathrm{O}_{2}$ and $\mathrm{CO}_{2}$, this trend having been determined during the period rebreathing air. In order to avoid the effect of the changes in blood flow which occur during the cardiac cycle (4) the corrections were made at the same phase in each cardiac cycle (the $R$ wave of the ECG).

The blood flow during a given interval of time is given by the following equation which is an application of the Fick principle for bloodflow (4) :

$$
\dot{\mathrm{Q}}=\frac{\Delta \mathrm{P} \cdot 60}{470 \cdot \mathrm{F}_{\mathrm{A} \cdot \mathrm{N}_{2} \mathrm{O}} \cdot \mathrm{P}_{\mathrm{cal}} \cdot \Delta \mathrm{t}}
$$

where $\Delta \mathrm{P}$ is the fall in plethysmographic pressure during an interval of time $\Delta t ; 470 \mathrm{ml}$. per $\mathrm{L}$. is the solubility coefficient for $\mathrm{N}_{2} \mathrm{O}$ in blood at $37^{\circ} \mathrm{C}$. $; \mathrm{F}_{\triangle \mathrm{N}_{2} \mathrm{O}}$ is the mean concentration ${ }^{6}$ of $\mathrm{N}_{2} \mathrm{O}$ in the expired alveolar air; $P_{\text {eal }}$ is the change in pressure in the plethysmograph for $1 \mathrm{ml}$.

6 The mean of expired alveolar $\mathrm{N}_{2} \mathrm{O}$ was measured at about mid-expiration. Systematic fluctuations of a few per cent $\mathrm{N}_{2} \mathrm{O}$ from the mean (as in Figure 3) were observed during the breathing cycle. Like $\mathrm{O}_{2}$ and $\mathrm{CO}_{2}(6)$, the mean during inspiration is probably very nearly the same as the mean $\mathrm{N}_{2} \mathrm{O}$ during expiration. The rate of change of alveolar concentration is about one-half per cent per second, (4), which introduces a slight systematic error in end-inspiratory and end-expiratory bloodflow. No attempt was made to correct the calculated bloodflow for respiratory fluctuations of $\mathrm{N}_{2} \mathrm{O}$ concentration. 
change in gas volume; and $\dot{Q}$ is the rate of blood flow in L. per minute.

\section{RESULTS}

\section{Normal quiet breathing}

Pulmonary capillary blood flow during inspiratory air flow, expiratory air flow, and for the whole respiratory cycle is tabulated as measured on five normal subjects (Table I). Each subject was measured on two different occasions. Beat-bybeat gas absorption throughout the respiratory cycle was plotted. The percentage deviations from mean blood flow of inspiratory blood flow and of expiratory blood flow are tabulated for individual subjects and averaged for the group of subjects. The results may be summarized as follows: for the group of subjects, the deviation of inspiratory blood flow from the mean blood flow was +1.8 per cent; S.D., 7.6 per cent; S.E., 2.4 per cent. The deviation of expiratory blood flow from the mean blood flow was -1.0 per cent; S.D., 7.7 per cent; S.E., 2.4 per cent. By the "t" test, the difference from mean blood flow and the difference between inspiratory and expiratory blood flow are not significant.

\section{Breathing through added resistance}

Similar measurements while breathing through added resistance are listed in Table II. No significant fluctuation was found.

\section{Slow breathing}

In subject A. B. DB., experiment No. 4 , the mean blood flow was $6 \mathrm{~L}$. per minute, and the heart

TABLE I

Pulmonary capillary blood flow during normal quiet respiration

\begin{tabular}{|c|c|c|c|c|c|c|}
\hline Subject & $\begin{array}{l}\text { Sub- } \\
\text { ject's } \\
\text { expt. }\end{array}$ & $\begin{array}{c}\text { Mean } \\
\dot{Q}\end{array}$ & $\begin{array}{l}\text { Insp. } \\
\dot{Q}\end{array}$ & Change & $\begin{array}{c}\text { Exp. } \\
\underset{Q}{0}\end{array}$ & Change \\
\hline \multirow[t]{2}{*}{$\begin{array}{l}\text { R. M. } \\
\text { A. B. DB. } \\
\text { J. S. - } \\
\text { G. B. } \\
\text { P. C. }\end{array}$} & $\begin{array}{c}\text { No. } \\
1 \\
2 \\
1 \\
2 \\
1 \\
2 \\
1 \\
2 \\
1 \\
2\end{array}$ & $\begin{array}{c}\text { L./min. } \\
4.7 \\
5.7 \\
3.5 \\
4.2 \\
7.0 \\
8.2 \\
7.8 \\
5.4 \\
6.6 \\
5.4\end{array}$ & $\begin{array}{c}L . / \min . \\
4.2 \\
6.1 \\
3.5 \\
4.1 \\
7.8 \\
8.8 \\
7.9 \\
5.8 \\
7.1 \\
4.9\end{array}$ & $\begin{array}{c}\% \\
-11 \\
+7 \\
0 \\
-2 \\
+11 \\
+7 \\
+1 \\
+7 \\
+7 \\
-9\end{array}$ & $\begin{array}{c}\text { L./min. } \\
5.2 \\
5.4 \\
3.3 \\
4.3 \\
6.6 \\
7.6 \\
7.5 \\
5.1 \\
6.3 \\
6.1\end{array}$ & $\begin{array}{r}\% \\
+11 \\
=5 \\
=6 \\
+5 \\
=6 \\
-7 \\
-4 \\
=6 \\
=5 \\
+13\end{array}$ \\
\hline & $\begin{array}{r}\text { Mean } \\
\text { S.D. } \\
\text { S.E. }\end{array}$ & $\begin{array}{l}5.9 \\
1.5 \\
0.5\end{array}$ & & $\begin{array}{r}+1.8 \\
7.6 \\
2.4\end{array}$ & & $\begin{array}{r}-1.0 \\
7.7 \\
2.4\end{array}$ \\
\hline
\end{tabular}

TABLE II

$$
\text { Pulmonary capillary blood flow while breathing }
$$
against added resistance

\begin{tabular}{lcccc}
\hline Subject & $\begin{array}{c}\text { Subject's } \\
\text { expt. }\end{array}$ & Mean $\dot{Q}$ & Insp. $\dot{Q}$ & Exp. $\dot{Q}$ \\
\hline & No. & L./min. & L./min. & L./min. \\
A. B. D B. & 3 & 4.1 & 4.06 & 4.3 \\
R. M. & 3 & 6.7 & 6.9 & 6.4 \\
\hline
\end{tabular}

rate was 74 per minute during slow breathing. There was an increase in blood flow to $7 \mathrm{~L}$. per minute toward the end of inspiratory gas flow and decrease toward the end of expiratory gas flow to $5 \mathrm{~L}$. per minute. Cardiac acceleration to 86 also occurred toward end inspiration, and deceleration to 62 toward end expiration.

\section{Atropine}

Of the two subjects given atropine, one performed at a normal respiratory rate and exhibited very little fluctuation of blood flow during the respiratory cycle (Figure 3 ) whereas the other subject, A. B. DB., breathed slowly and showed fluctuations of blood flow similar to slow breathing without atropine (see above) except that sinus arrhythmia disappeared. These few measurements seem to indicate that further studies of the effects of different breathing patterns, drugs, and disease may be of interest.

\section{DISCUSSION}

The evidence presented above leads directly to the conclusion that the exchange of inert, soluble gas between the alveoli and capillaries continues to occur evenly during both inspiration and expiration. Furthermore, it is apparent that pulmonary capillary blood flow does not vary, or varies within narrow limits, throughout the respiratory cycle in normal man.

During the "direct Fick" determination of blood flow it is generally assumed that the respiratory fluctuations of blood flow and alveolar gas tensions do not cause any appreciable error in the measurement of blood flow. The above data show that this is a safe assumption for the lung capillaries, but this does not rule out errors due to fluctuations of blood flow at other sites of blood sampling.

It has been calculated, assuming constant blood flow throughout the respiratory cycle, that there are respiratory fluctuations of alveolar $\mathrm{P}_{\mathrm{OO}_{2}}$ and 
$\mathrm{P}_{\mathrm{O}_{2}}$ amounting to a few $\mathrm{mm}$. $\mathrm{Hg}$ of partial pressure (6). The assumption concerning blood flow has now been tested and shown to be reasonably accurate for a normal rate of breathing. However, slow, deep breathing may cause a variation of blood flow such as to slightly diminish the predicted respiratory excursions of alveolar gas tension.

In the introductory paragraphs it was mentioned that certain hemodynamic measurements tended to indicate the possibility of respiratory variations of pulmonary blood flow and vascular resistance. We have not made simultaneous determinations of pulmonary vascular pressure in our subjects, and direct measurements of blood velocity in the great vessels have not been attempted under similar experimental conditions in humans. Knowledge of the mechanical properties of the pulmonary arteries, capillaries and veins is not yet sufficient to allow interpretation of pressure and capillary blood flow in terms of resistance to flow even had they been measured simultaneously, because pressure and flow are pulsatile and not exactly simultaneous with each other. Therefore the following part of the discussion, which is a comparison of our results with the results of others, must be considered as speculative until further investigation of the problems.

It has been shown that the effective pulmonary arterial pressure (i.e., in relation to intrapleural pressure) is raised during inspiration $(2,7,8)$, whereas the effective left auricular pressure measured by others (as discussed in Reference 2) shows little change so that pressure difference between these vessels is therefore augmented during inspiration. The rise in effective pulmonary arterial pressure has been supposed by some ( 8 ) to be due entirely to the increased output of the right heart during inspiration, since it still occurs when sympathetic nerve action is blocked by tetraethyl ammonium bromide. An increase in the cardiac output of normal subjects, or increase in blood flow through one lung due to clamping the other pulmonary artery, is accompanied by either no rise or only a slight rise in pulmonary arterial pressure. For this reason Brecher and Hubay (3) considered that the small increase in cardiac output which occurred during inspiration was insufficient to account for the rise in pulmonary arterial pressure, and that some increase in pulmonary vascu- lar resistance must be postulated. This increased resistance is probably not due to vasomotor activity (9) but could be due to mechanical changes in the lung vessels during inflation.

Daly (10) found that inflation of the lungs decreased vascular resistance but most workers have found that in the lungs, either isolated or in situ, when the vascular pressure is maintained constant in relation to intrapleural pressure, the vascular resistance increases on inflation $(7,11,12)$. Direct observation of the lung capillaries in the rat (13) shows that during inspiration the capillaries become flatter and the blood flow in them usually diminishes, probably indicating increased vascular resistance. During normal inspiration the increased output of the right heart must be accommodated by distension of the pulmonary arteries.

During inspiration there is a fall in systemic blood pressure, even when this is measured relative to intrapleural pressure $(2,7,12,14-18)$, and oncometer and cinematographic studies of the heart (16) have shown that this is associated with a diminished left ventricular output and left ventricular diastolic volume. A diminished left atrial size has also been reported during inspiration (14), as would be expected if the diminished left ventricular output is due to decreased filling. Since the blood flow into the capillaries is not diminished during inspiration there must be an increase of blood volume in either the pulmonary capillaries or pulmonary veins. The site of this increase in capacity has not been determined and the evidence is conflicting. Direct observations of the lung capillaries (13) show that they are flattened during inspiration and their volume does not appear to increase. Heinbecker (12), in perfusion studies in which lungs were inflated with positive pressure, also concluded that the capacity of the capillaries was decreased on inspiration. Some workers $(17,19)$ have found an increased blood volume in the lungs during inspiration, but the experiments were carried out under conditions such that there was an increased pressure across the walls of the pulmonary veins during inspiration and dilatation of these may have accounted for the increased capacity. In the intact chest there is no other reason why the increased negative intrathoracic pressure should dilate the part of the pulmonary veins outside the lung parenchyma.

In summary, it may be said that the increased 


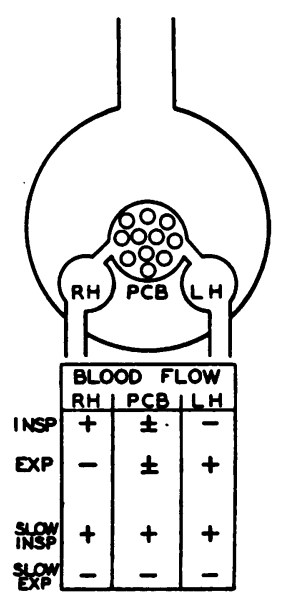

Fig. 4. Schematic Representation of the Blood Flow Through the Different Blood Compartments IN the Thorax DURING INSPIRATION AND ExpIRATION at Normal and Slow Rates

$\mathrm{RH}=$ right heart (including pulmonary arterial tree); $\mathrm{PCB}=$ pulmonary capillary bed $; \mathrm{LH}=$ left heart (including pulmonary veins). The change of blood flow is indicated by + (increase), - (decrease), and \pm (no change).

pulmonary artery pressure which occurs during inspiration is probably due partly to an increased output of the right side of the heart and partly to an increased resistance to pulmonary blood flow; as a result, the flow into the capillaries is constant. The reduction of the output of the left heart which occurs a beat or two later can only be explained on the basis of an increased capacity of the pulmonary capillaries or veins but the exact location of this increased capacity and its mechanism are not understood.

When the breathing is slower and deeper it is probable that the increased cardiac output, due to an increased venous return, is greater than can be accommodated by distension of the pulmonary arterial system and the balance between cardiac output and pulmonary vascular resistance is upset, resulting in an increase in pulmonary capillary blood flow towards the end of inspiration. The increased cardiac output is due mainly to increase in stroke volume since the effect is not abolished when the sinus arrhythmia is prevented with atropine. Figure 4 is a schematic diagram which attempts to summarize the findings reported in this paper, and their relationship to the work discussed in the preceding paragraphs.

\section{REFERENCES}

1. Wiggers, C. J., The regulation of the pulmonary circulation. Physiol. Rev., 1921, 1, 239.
2. Lauson, H. D., Bloomfield, R. A., and Cournand, A., The influence of the respiration on the circulation in man, with special reference to pressures in the right auricle, right ventricle, femoral artery and peripheral veins. Am. J. Med., 1946, 1, 315.

3. Brecher, G. A., and Hubay, C. A., Pulmonary blood flow and venous return during spontaneous respiration. Circ. Research, 1955, 3, 210.

4. Lee, G. de J., and DuBois, A. B., Pulmonary capillary blood flow in man. J. Clin. Invest., 1955, 34, 1380.

5. DuBois, A. B., Botelho, S. Y., and Comroe, J. H., Jr., A new method for measuring airway resistance in man using a body plethysmograph: Values in normal subjects and in patients with respiratory disease. J. Clin. Invest., 1956, 35, 327.

6. DuBois, A. B., Alveolar $\mathrm{CO}_{2}$ and $\mathrm{O}_{2}$ during breath holding, expiration, and inspiration. J. Applied Physiol., 1952, 5, 1.

7. Bjurstedt, H., and Hesser, C. M., Effects of lung inflation on the pulmonary circulation in anesthetized dogs. Acta physiol. Scandinav., 1953, 29, 180.

8. Lee, G. de J., Matthews, M. B., and Sharpey-Schafer, E. P., The effect of the Valsalva manoeuvre on the systemic and pulmonary arterial pressure in man. Brit. Heart J., 1954, 16, 311.

9. Baxter, I. B., and Pearce, J. W., Simultaneous measurement of pulmonary arterial flow and pressure using condensor manometers. J. Physiol., 1951, $115,410$.

10. Daly, I. de B., The resistance of the pulmonary vascular bed. J. Physiol., 1930, 69, 238.

11. Edwards, W. S., The effects of lung inflation and epinephrine on pulmonary vascular resistance. Am. J. Physiol., 1951, 167, 756.

12. Heinbecker, P., The mechanism of the respiratory waves in systemic arterial blood pressure. Am. J. Physiol., 1927, 81, 170.

13. Ramos, J. G., On the dynamics of the lung's capillary circulation. I. The mechanical factors. Am. Rev. Tuberc., 1955, 71, 822.

14. Cahoon, D. H., Michael, I. E., and Johnson, V., Respiratory modification of the cardiac output. Am. J. Physiol., 1941, 133, 642.

15. Osgood, H., Blood pressure fluctuations in respiratory obstruction; experimental observations. J. Lab. \& Clin. Med., 1942, 27, 1536.

16. Shuler, R. H., Ensor, C., Gunning, R. E., Moss, W. G., and Johnson, V., Differential effects of respiration on the left and right ventricles. Am. J. Physiol., 1942, 137, 620.

17. Trimby, R. H., and Nicholson, H. C., Some observations on the nature of the respiratory waves in arterial blood pressure. Am. J. Physiol., 1940, 129, 289.

18. Boyd, T. E., and Patras, M. C., Variations in filling and output of the ventricles with the phases of respiration. Am. J. Physiol., 1941, 134, 74.

19. Dupee, C., and Johnson, V., Respiratory changes in pulmonary vascular capacity. Am. J. Physiol., 1943, 139, 95. 